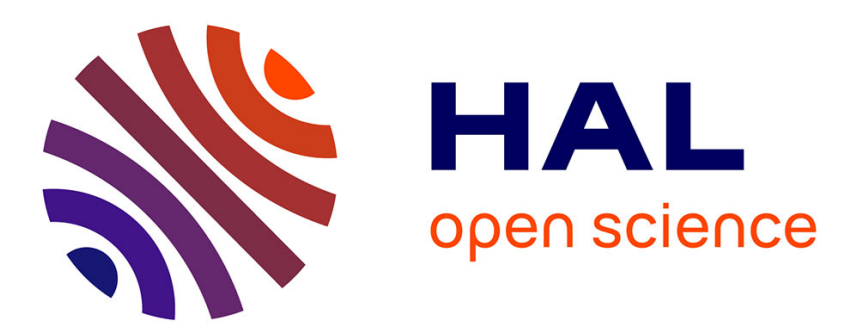

\title{
An Alternative Estimation Procedure For Partial Least Squares Path Modeling
}

Heungsun Hwang, Yoshio Takane, Arthur Tenenhaus

\section{To cite this version:}

Heungsun Hwang, Yoshio Takane, Arthur Tenenhaus. An Alternative Estimation Procedure For Partial Least Squares Path Modeling. Behaviormetrika, 2015, 42 (1), pp.63-78. 10.2333/bhmk.42.63 . hal-01235744

\section{HAL Id: hal-01235744 \\ https://hal-centralesupelec.archives-ouvertes.fr/hal-01235744}

Submitted on 3 Dec 2015

HAL is a multi-disciplinary open access archive for the deposit and dissemination of scientific research documents, whether they are published or not. The documents may come from teaching and research institutions in France or abroad, or from public or private research centers.
L'archive ouverte pluridisciplinaire HAL, est destinée au dépôt et à la diffusion de documents scientifiques de niveau recherche, publiés ou non, émanant des établissements d'enseignement et de recherche français ou étrangers, des laboratoires publics ou privés. 


\title{
AN ALTERNATIVE ESTIMATION PROCEDURE FOR PARTIAL LEAST SQUARES PATH MODELING
}

\author{
Heungsun Hwang ${ }^{\star}$, Yoshio Takane ${ }^{* *}$, and Arthur Tenenhaus ${ }^{* * *}$
}

Since its inception, partial least squares path modeling has suffered from the absence of a single optimization criterion for estimating component weights. A new estimation procedure is proposed to address this enduring issue. The proposed procedure aims to minimize a single least squares criterion for estimating component weights under both Mode A and Mode B. An alternating least squares algorithm is developed to minimize the criterion. This procedure provides quite similar or identical solutions to those obtained from existing Lohmöller's algorithm in real and simulated data analyses. The proposed procedure can serve as an alternative to the existing one in that it is well-grounded in theory as well as performs comparably in practice.

\section{Introduction}

Partial least squares path modeling (PLSPM) (Wold, 1966, 1973, 1982; Lohmöller 1989) is a long-standing approach to structural equation modeling. In parameter estimation, this approach adopts a strategy of estimating a latent variable as a component or weighted composite of indicators. In this regard, PLSPM can be considered a component-based approach to structural equation modeling (Tenenhaus, 2008). It carries out two main stages sequentially to estimate parameters. The first stage estimates latent variables as components, which requires the estimation of component weights. This stage uses an iterative algorithm to estimate the component weights. The second stage estimates remaining parameters in measurement and structural models (i.e., path coefficients and/ or loadings) by means of ordinary linear regression. That is, path coefficients are estimated by regressing each dependent latent variable on its explanatory latent variables, whereas loadings are estimated by regressing indicators on their corresponding latent variables. The second stage is thus non-iterative, which is based on the latent variables obtained from the first stage. Accordingly, the first stage is the most crucial estimation procedure in PLSPM (Hanafi, 2007).

Lohmöller's (1989) algorithm is best known for the first stage and implemented into most software programs for PLSPM, including LVPLS (Lohmöller, 1984), PLS Graph (Chin, 2001), SmartPLS (Ringle et al., 2005), and XLSTAT (Addinsoft, 2009). As will be explained in more detail in Section 2, this algorithm repeats two steps, called

\footnotetext{
Key Words and Phrases: Partial least squares path modeling, Mode A, Mode B, schemes, optimization criterion, alternating least squares.

* McGill University

** University of Victoria

*** CentraleSupelec-L2S, UMR CNRS 8506 and Bioinformatics/Biostatistics P latform IHU-A-ICM

Mail Address: heungsun.hwang@mcgill.ca

The authors wish to thank Claes Fornell for providing the ACSI data. Requests for reprints should be sent to: Heungsun Hwang, Department of Psychology, McGill University, 1205 Dr. Penfield Avenue, Montreal, QC, H3A 1B1, Canada. Tel: 514-398-8021.
} 
internal and external estimation. In the internal estimation step, a so-called inner estimate or inner component is obtained for each latent variable under different schemes such as centroid, factorial, and path weighting. In the external estimation step, component weights for each block of indicators are estimated in two different ways called Mode A and Mode B.

It is not known which criterion the Lohmöller algorithm aims to optimize by repeating the two steps (e.g., Coolen \& de Leeuw, 1987; Jöreskog \& Wold, 1982). A few attempts have been made to address this issue. For example, Hanafi (2007) presented association-maximization criteria for the centroid and factorial schemes under Mode B (also see Tenenhaus \& Tenenhaus, 2011). To our knowledge, nevertheless, no single optimization criterion is yet available for the algorithm, which includes both Mode $\mathrm{A}$ and Mode B as special cases. The lack of a single optimization criterion makes it difficult to evaluate the algorithm (McDonald, 1996).

In this paper, we propose an alternative procedure for the first estimation stage of PLSPM. The proposed procedure aims to minimize a single least squares criterion for estimating component weights under both Mode A and Mode B. An alternating least squares (ALS) algorithm is used to minimize the criterion, which repeats the same two steps used in the Lohmöller algorithm. A major difference is that the ALS algorithm updates the inner estimates and component weights optimally by minimizing the least squares criterion. Consequently, the proposed procedure is well-defined in a least squares sense.

The paper is organized as follows. In Section 2, we provide a brief description of the existing Lohmöller algorithm. In Section 3, we provide a detailed account of the proposed procedure. In Section 4, we investigate the performance of the proposed and extant procedures through the analyses of real and simulated data. In the final section, we discuss implications of the proposed procedure.

\section{Existing P LSP M Algorithm}

We briefly describe the Lohmöller algorithm. Refer to Tenenhaus et al. (2005) for a fuller description of the algorithm.

Let $\eta_{j}$ denote an $N$ by 1 vector of the $j$ th latent variable $(j=1, \ldots, J)$, where $N$ is the number of individuals. Let $\mathrm{X}_{\mathrm{j}}$ denote an $\mathrm{N}$ by $\mathrm{P}_{\mathrm{j}}$ matrix consisting of a block of indicators associated with $\eta_{j}$. Let $w_{j}$ denote a $P_{j}$ by 1 vector of component weights assigned to $X_{j}$. In PLSPM, conventionally, both indicators and latent variables are assumed to be standardized, such that they have zero means and unit variances (e.g., $\left.\eta_{j} \eta_{j}=N\right)$. However, they are to be normalized here, so that their length is equal to one (e.g., $\eta_{j} \eta_{j}=1$ ). This normalization makes the exposition of equations simpler while producing identical estimates of weights, path coefficients, and loadings. The individual scores of standardized latent variables can always be obtained by multiplying their normalized scores by $\bar{N}$.

The Lohmöller algorithm begins by choosing arbitrary initial values for $\mathrm{w}_{j}$ and computing $\eta_{j}=X_{j} w_{j}$. Then, it repeats the following two steps to estimate $w_{j}$ and 
$\eta_{\mathrm{j}}$.

Step 1 (internal estimation): Update the inner estimate for $\eta_{j}$. The inner estimate, denoted here by $f_{j}$, is a weighed composite of the latent variables connected to $\eta_{j}$ in a given structural model. Such connected latent variables contain those affecting $\eta_{j}$ as well as those being affected by $\eta_{j}$. The inner estimate takes the general form as follows.

$$
f_{j}={ }_{q=1}^{Q_{j}} e_{q} \eta_{q},
$$

where $e_{q}$ is a scalar value, called the inner weight, which is assigned to each of the $Q_{j}$ latent variables $\left(\eta_{q}\right.$ 's) that are connected to $\eta_{j}$. As shown in (1), updating the inner estimate amounts to updating its inner weights, given latent variables. Three different ways, so-called schemes, are available for the calculation of the inner weights: centroid (Wold, 1982), factorial (Lohmöller, 1989), and path weighting. In the centroid scheme, $e_{q}$ 's are the signs of the correlations between $\eta_{q}$ 's and $\eta_{j}$. In the factorial scheme, $e_{q}$ 's are the correlations between $\eta_{q}$ 's and $\eta_{j}$. In the path weighting scheme, $e_{q}$ 's are the regression coefficients of $\eta_{j}$ on $\eta_{q}$ 's if $\eta_{j}$ is a dependent variable, whereas they are the correlations between $\eta_{q}$ 's and $\eta_{j}$ if $\eta_{j}$ is an explanatory variable. The path weighting scheme is recommended over the other schemes because it takes into account both directions and magnitudes of the relationships between latent variables (Esposito Vinzi et al., 2010).

Figure 1 displays a prototype, structural model to illustrate the first step. This model consists of four latent variables $(\mathrm{J}=4)$. For the prototype model, the inner estimate for each of the four latent variables is given as

$$
\begin{aligned}
& f_{1}=e_{13} \eta_{3} \\
& f_{2}=e_{23} \eta_{3} \\
& f_{3}=e_{31} \eta_{1}+e_{32} \eta_{2}+e_{34} \eta_{4} \\
& f_{4}=e_{43} \eta_{3}
\end{aligned}
$$

As explained above, the inner weights for these inner estimates are calculated based on which scheme is chosen. For example, if the path weighting scheme is adopted, $e_{31}$ and $e_{32}$ are the regression coefficients of $\eta_{3}$ on $\eta_{1}$ and $\eta_{2}$, because $\eta_{1}$ and $\eta_{2}$ are explanatory variables for $\eta_{3}$, whereas $e_{34}$ are the correlation between $\eta_{3}$ and $\eta_{4}$, because $\eta_{3}$ is an explanatory variable for $\eta_{4}$. All the other inner weight estimates are simply correlations between two connected latent variables, because all latent variables are normalized and the regression coefficient of one latent variable on the other is equivalent to the correlation between them.

Step 2 (external estimation): Update $\mathrm{w}_{\mathrm{j}}$. There are two ways of estimating component weights on the basis of the nature of the measurement model: Mode A and Mode B. Mode A is known to be more suitable for reflective indicators, whereas Mode B is for formative indicators (e.g., Tenenhaus et al., 2005). Specifically, under Mode A, $\mathrm{w}_{\mathrm{j}}$ is updated by regressing $\mathrm{X}_{\mathrm{j}}$ on $\mathrm{f}_{\mathrm{j}}$, as follows.

$$
w_{j}=X_{j} f_{j}\left(f_{j} f_{j}\right)^{-1} \text {. }
$$




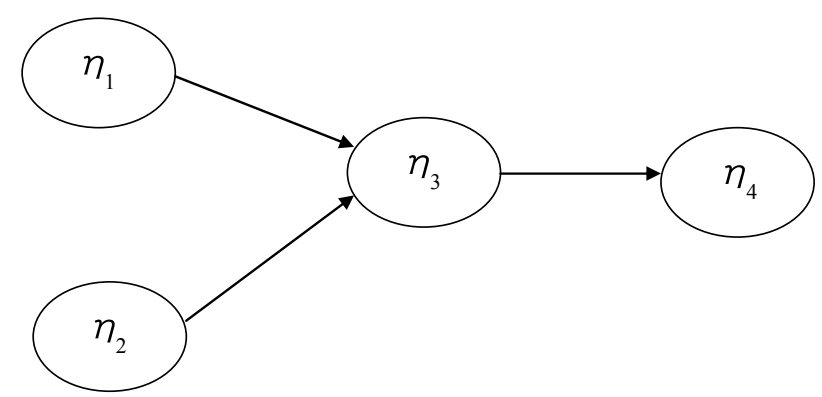

Figure 1: A prototype structural model that involves four latent variables. No residual terms are displayed.

Under Mode $B, w_{j}$ is updated by regressing $f_{j}$ on $X_{j}$, as follows.

$$
w_{j}=\left(X_{j} X_{j}\right)^{-1} X_{j} f_{j} .
$$

Subsequently, $\eta_{j}$ is updated by $\eta_{j}=X_{j} w_{j}$, and normalized such that $\eta_{j} \eta_{j}=$ $\mathrm{w}_{\mathrm{j}} \mathrm{X}_{\mathrm{j}} \mathrm{X}_{\mathrm{j}} \mathrm{w}_{\mathrm{j}}=1$. This normalization can be done by multiplying $\mathrm{w}_{\mathrm{j}}$ by $\left(w_{j} X_{j} X_{j} w_{j}\right)^{-1 / 2}$, indicating that the effect of $\left(f_{j} f_{j}\right)^{-1}$ in (3) will be cancelled out. Consequently, under Mode $\mathrm{A}, \mathrm{w}_{\mathrm{j}}$ can be updated simply by

$$
w_{j}=X_{j} f_{j} .
$$

The above steps are repeated until no substantial differences occur between the previous and current weight estimates for all $\mathrm{J}$ blocks of indicators. A summary of this algorithm is provided in the Appendix.

As stated earlier, it is unknown which optimization criterion the Lohmöller algorithm seeks to maximize or minimize under Mode A and Mode B. In the next section, we propose a single least squares criterion that is to be consistently minimized for estimating component weights under both modes.

\section{The Proposed Estimation Procedure for P LSP M}

Let $\mathrm{H}=\left[\eta_{1}, \ldots, \eta_{J}\right]$ denote an $\mathrm{N}$ by $\mathrm{J}$ matrix consisting of all $\mathrm{J}$ latent variables. Let $\varepsilon_{j}$ denote a $J$ by 1 vector consisting of $Q_{j}$ inner weights for the $Q_{j}$ latent variables connected to $\eta_{j}$, and of $J-Q_{j}$ zeros for the remaining unconnected latent variables. Then, let $f_{j}=H \varepsilon_{j}$ denote an $N$ by 1 vector of the inner estimate for $\eta_{j}$. For example, in the prototype model depicted in Figure $1, H=\left[\eta_{1}, \eta_{2}, \eta_{3}, \eta_{4}\right], \varepsilon_{1}=\left[0,0, e_{13}, 0\right]$, $\varepsilon_{2}=\left[0,0, e_{23}, 0\right], \varepsilon_{3}=\left[e_{31}, e_{32}, 0, e_{34}\right]$, and $\varepsilon_{4}=\left[0,0, e_{43}, 0\right]$.

We propose a least squares criterion for estimating all weights under Mode A, as follows.

$$
\text { Minimize } \varphi_{A}={ }_{j=1}^{J} S S\left(X_{j}-f_{j} w_{j}\right),
$$

subject to $\eta_{j} \eta_{j}=1$, where $\operatorname{SS}(M)=\operatorname{trace}(M M)$ for any matrix $M$. This criterion appears similar to a blockwise join loss function for principal component analysis 
(Gifi, 1990, p. 152), where a vect or of object scores is replaced by the inner estimate.

We propose a least squares criterion for estimating all weights under Mode B, as follows.

$$
\text { Minimize } \varphi_{B}={ }_{j=1}^{J} S S\left(f_{j}-X_{j} w_{j}\right)
$$

subject to $\eta_{j} \eta_{j}=1$. Criterion (7) may be viewed as a blockwise meet loss version (Gifi, 1990, p. 167) of the covariance-maximization criterion for regularized generalized canonical correlation analysis (Tenenhaus \& Tenenhaus, 2011).

Let $\alpha_{j}$ denote a binary value that indicates which mode is used for updating the component weights for the $\mathrm{j}$ th block of indicators. That is, $\alpha_{j}=1$ if Mode A is used, and $\alpha_{j}=0$ if Mode B is used. We then develop a single optimization criterion for the PLSPM algorithm by combining (6) and (7), as follows.

$$
\operatorname{Minimize} \varphi={ }_{j=1}^{J} \alpha_{j} \operatorname{SS}\left(X_{j}-f_{j} w_{j}\right)+{ }_{j=1}^{J}\left(1-\alpha_{j}\right) \operatorname{SS}\left(f_{j}-X_{j} w_{j}\right),
$$

subject to $\eta_{j} \eta_{j}=1$. This criterion subsumes (6) and (7) as special cases by setting all $\alpha_{j}$ 's to one or zero, respectively. Moreover, it can be used for estimating the weights for each block of indicators under either Mode A or Mode B by setting the corresponding $\alpha_{j}$ to one or zero, respectively.

We develop an ALS algorithm to minimize (8). This algorithm begins by assigning arbitrary initial values to $w_{j}$ and obtaining $\eta_{j}=X_{j} w_{j}$. Then, it alternates the following two steps.

Step 1 (internal estimation): Update $\mathrm{f}_{\mathrm{j}}$ for fixed $\mathrm{w}_{\mathrm{j}}$. This step reduces to updating the inner weights in $\varepsilon_{\mathrm{j}}$, given latent variables. It is equivalent to minimizing

$$
\varphi_{j}=\alpha_{j} S S\left(X_{j}-H \varepsilon_{j} w_{j}\right)+\left(1-\alpha_{j}\right) S S\left(H \varepsilon_{j}-\eta_{j}\right) .
$$

Let $e_{j}$ denote a $Q_{j}$ by 1 vector consisting of non-zero inner weights only. Let $\Gamma_{j}$ denote an $N$ by $Q_{j}$ matrix formed by eliminating the columns of $H$ corresponding to any zero elements in $\varepsilon_{j}$. Then, minimizing (9) is equivalent to minimizing

$$
\varphi_{j}=\alpha_{j} S S\left(X_{j}-\Gamma_{j} e_{j} w_{j}\right)+\left(1-\alpha_{j}\right) S S\left(\Gamma_{j} e_{j}-\eta_{j}\right) .
$$

By solving $\frac{1}{2} \frac{\partial \varphi_{j}}{\partial e_{j}}=0$, the least squares estimate of $e_{j}$ is obtained as

$$
e_{j}=\alpha_{j} w_{j} w_{j} \Gamma_{j} \Gamma_{j}+\left(1-\alpha_{j}\right) \Gamma_{j} \Gamma_{j}^{-1} \Gamma_{j} \eta_{j} .
$$

Then, $\mathrm{f}_{\mathrm{j}}$ is updated by $\mathrm{f}_{\mathrm{j}}=\mathrm{H} \varepsilon_{\mathrm{j}}$, where $\varepsilon_{\mathrm{j}}$ is constructed from the estimate of $\mathrm{e}_{\mathrm{j}}$. Step 2 (external estimation): Update $\mathrm{w}_{\mathrm{j}}$ for fixed $\mathrm{f}_{\mathrm{j}}$. This is equivalent to minimizing

$$
\varphi_{j}=\alpha_{j} S S\left(X_{j}-f_{j} w_{j}\right)+\left(1-\alpha_{j}\right) S S\left(f_{j}-X_{j} w_{j}\right) .
$$

Note that in (12), $f_{j}$ does not involve $w_{j}$ because $\eta_{j}$ is not connected with itself. 
By solving $\frac{1}{2} \frac{\partial \varphi_{j}}{\partial w_{j}}=0$, the least squares estimate of $w_{j}$ is obtained as

$$
w_{j}=a_{j} f_{j} f_{j} I+\left(1-a_{j}\right) X_{j} X_{j}{ }^{-1} X_{j} f_{j},
$$

where $I$ is an identity matrix of size $P_{j}$. Subsequently, $\eta_{j}$ is updated by $\eta_{j}=X_{j} w_{j}$, and normalized. We repeat the two steps until the difference in the values of (8) between the previous and current iterations decreases below a pre-determined threshold (e.g., .00001). A summary of the ALS algorithm is also presented in the Appendix.

A few remarks concerning the ALS algorithm are in order. First, it is easily seen that if Mode A is used or equivalently $\alpha_{j}=1,(13)$ reduces to (3) and (5), whereas if Mode B is used or $\alpha_{j}=0,(13)$ reduces to (4). This indicates that the algorithm deals with Mode A and Mode B as special cases. Second, in the first step, the estimates of the inner weights are obtained in such a way that they minimize a least squares criterion, conditionally upon the estimates of component weights. Thus, we may call the step the "least squares scheme." On the other hand, it is uncertain which criterion the existing schemes seek to optimize except for a few special cases (Hanafi, 2007; Tenenhaus \& Tenenhaus, 2011). Third, the ALS algorithm defines convergence as the decrease in the value of the optimization criterion (8) beyond a certain threshold, whereas the Lohmöller algorithm defines convergence as a sort of equilibrium, i.e., the point at which no substantial difference occurs between the previous and current estimates of weights, because it does not involve an optimization criterion. Lastly, at least in theory, a third type of mode can be considered by taking any value of $\alpha_{j}$ between 0 and 1 . For example, by specifying $\alpha_{j}=.1$, the second term of the criterion can have a greater influence on the estimation of component weights. However, in practice, it is not yet clear what such types of mode connote and whether using them is sensible substantively.

\section{Empirical Comparisons}

In this section, we compare the proposed procedure to the extant procedure based on the Lohmöller algorithm, using real and simulated data.

\subsection{Real Data Analysis}

We applied the proposed and extant procedures to fit the American customer satisfaction index (ACSI) model (Fornell et al., 1996) to a consumer-level dataset collected in 2002. This dataset consists of the responses of 774 consumers to the service units (e.g., police, garbage pick-up services, etc.) within the US sector of public administration.

The ACSI model specifies the relationships among antecedent and consequent latent variables of customer satisfaction. As depicted in Figure 2, the ACSI model includes fourteen indicators: $\mathrm{x}_{1}=$ customer expectations about overall quality, $\mathrm{x}_{2}=$ customer expectations about reliability, $\mathrm{x}_{3}=$ customer expectations about customization, $\mathrm{x}_{4}$ 
$=$ overall quality, $\mathrm{x}_{5}=$ reliability, $\mathrm{x}_{6}=$ customization, $\mathrm{x}_{7}=$ price given quality, $\mathrm{x}_{8}=$ quality given price, $\mathrm{x}_{9}=$ overall customer satisfaction, $\mathrm{x}_{10}=$ confirmation of expectations, $\mathrm{x}_{11}=$ distance to ideal product or service, $\mathrm{x}_{12}=$ formal or informal complaint behavior, $\mathrm{x}_{13}=$ repurchase intention, and $\mathrm{x}_{14}=$ price tolerance. The measures and scales of these indicators are available in Fornell et al. (1996). The ACSI model also involves six latent variables that underlie the fourteen indicators, as follows: $\mathrm{CE}=$ customer expectations, $\mathrm{PQ}=$ perceived quality, $\mathrm{PV}=$ perceived value, $\mathrm{CS}=$ customer satisfaction, $\mathrm{CC}=$ customer complaints, and $\mathrm{CL}=$ customer loyalty.

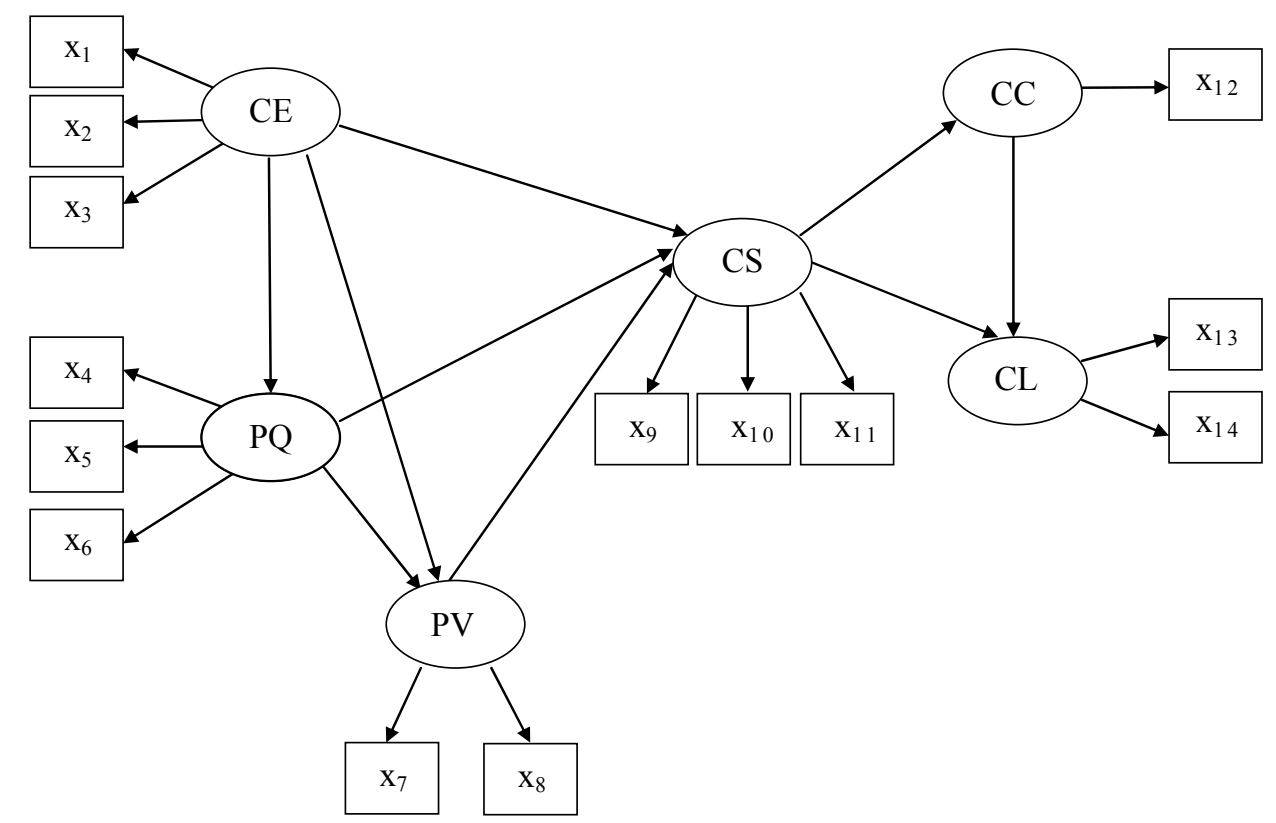

Figure 2: The American customer satisfaction index model. No residual terms are displayed.

We used SmartPLS (Ringle et al., 2005) to implement the extant procedure in combination with the path weighting scheme. As displayed in Figure 2, the ACSI model assumes that all indicators are reflective. This suggests that Mode A should be more appropriate for estimating weights.

Tables 1 and 2 present the estimates of weights, loadings, and path coefficients obtained from the proposed and extant procedures under Mode A. As shown in the tables, both procedures resulted in quite similar parameter estimates, leading to the same interpretations.

\subsection{Simulated Data Analysis}

We further compared the performance of the proposed and extant procedures based on simulated data. In particular, we focused on how similarly the proposed and extant procedures would perform under two different models. 
Table 1: The estimates of weights and loadings of the ACSI model obtained from the proposed and extant proceduresfor PLSPM.

\begin{tabular}{|c|c|c|c|c|c|}
\hline \multirow{2}{*}{ Latent } & \multirow{2}{*}{ Indicator } & \multicolumn{2}{|c|}{ Weight estimates } & \multicolumn{2}{c|}{ Loading est imates } \\
\cline { 3 - 6 } & & Proposed & Extant & Proposed & Extant \\
\hline CE & $\mathrm{x}_{1}$ & .4447 & .4523 & .8651 & .8679 \\
& $\mathrm{x}_{2}$ & .4375 & .4310 & .8772 & .8750 \\
& $\mathrm{x}_{3}$ & .3219 & .3207 & .7189 & .7179 \\
\hline PQ & $\mathrm{x}_{4}$ & .4042 & .4048 & .9336 & .9328 \\
& $\mathrm{x}_{5}$ & .4114 & .4034 & .9325 & .9303 \\
& $\mathrm{x}_{6}$ & .2986 & .3072 & .8004 & .8045 \\
\hline $\mathrm{PV}$ & $\mathrm{x}_{7}$ & .4251 & .4229 & .8024 & .8012 \\
& $\mathrm{x}_{8}$ & .7060 & .7080 & .9332 & .9339 \\
\hline $\mathrm{CS}$ & $\mathrm{x}_{9}$ & .3851 & .3855 & .9388 & .9387 \\
& $\mathrm{x}_{10}$ & .3480 & .3414 & .9232 & .9216 \\
& $\mathrm{x}_{11}$ & .3487 & .3550 & .9097 & .9113 \\
\hline $\mathrm{CC}$ & $\mathrm{x}_{12}$ & 1.000 & 1.000 & 1.000 & 1.000 \\
\hline $\mathrm{CL}$ & $\mathrm{x}_{13}$ & .5827 & .5827 & .9507 & .9507 \\
& $\mathrm{x}_{14}$ & .4812 & .4813 & .9268 & .9268 \\
\hline
\end{tabular}

Table 2: The estimates of path coefficients of the ACSI model obtained from the proposed and extant procedures for PLSPM.

\begin{tabular}{|l|r|r|}
\hline & Proposed & \multicolumn{1}{c|}{ Extant } \\
\hline $\mathrm{CE} \rightarrow \mathrm{PQ}$ & .5822 & .5819 \\
$\mathrm{CE} \rightarrow \mathrm{PV}$ & .1220 & .1230 \\
$\mathrm{CE} \rightarrow \mathrm{CS}$ & .0330 & .0353 \\
$\mathrm{PQ} \rightarrow \mathrm{PV}$ & .6469 & .6466 \\
$\mathrm{PQ} \rightarrow \mathrm{CS}$ & .6707 & .6668 \\
$\mathrm{PV} \rightarrow \mathrm{CS}$ & .2656 & .2676 \\
$\mathrm{CS} \rightarrow \mathrm{CC}$ & -.4000 & -.4002 \\
$\mathrm{CS} \rightarrow \mathrm{CL}$ & .5824 & .5831 \\
$\mathrm{CC} \rightarrow \mathrm{CL}$ & -.0976 & -.0972 \\
\hline
\end{tabular}

\subsubsection{Simulation 1}

Figure 3 displays the structural equation model considered in the first simulation study, along with its unstandardized and standardized parameter values. In this model, three latent variables were specified, each of which underlay three indicators. Individual-level multivariate normal data were drawn from $\mathrm{N}(0, \Sigma)$, where $\Sigma$ is the implied population covariance matrix derived based on the unstandardized parameter values in the framework of covariance structure analysis (e.g., Jöreskog, 1970). This indicates that the latent variables in the model were assumed to be equivalent to common factors.

We considered three different levels of sample size $(N=25,100,400)$. Five hundred samples were generated at each sample size. We used the same initial values per sample for the proposed and extant procedures. In the model, all indicators were reflective, so that we used Mode A for both procedures. The path weighting scheme was employed for the extant procedure. 


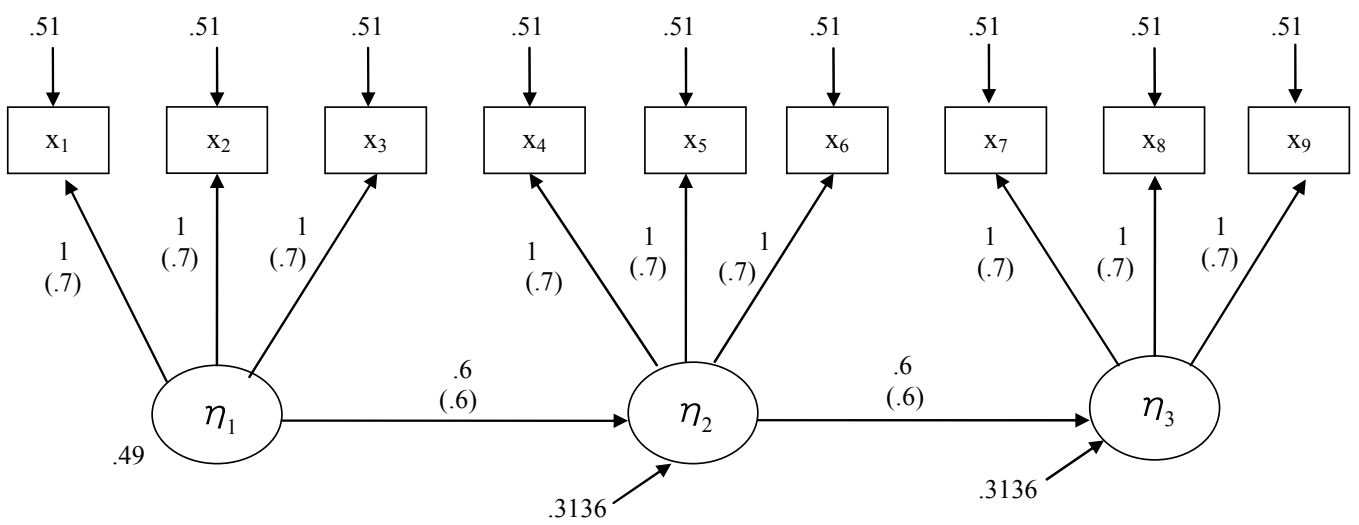

Figure 3: The structural equation model specified for the first simulation study. Standardized parameters are given in parentheses.

PLSPM provides standardized parameter estimates. Table 3 presents the bias, standard deviation, and mean square error of each standardized parameter estimate obtained from the two procedures. As shown in the table, the parameter estimates of both procedures shared the same properties. In general, their loading estimates were positively biased, whereas their path coefficients were negatively biased. As stated above, in this study, the simulated data were generated under the assumption that a latent variable was equivalent to a common factor. Under this assumption, PLSPM is known to yield biased estimates (e.g., Dijkstra, 2010) because it regards latent variables as components rather than common factors. The standard deviations of the loading and path coefficient estimates decreased with sample size. The mean square errors of these estimates became closer to zero with sample size. Notably, all the parameter estimates obtained from both procedures exhibited quite similar biases, standard deviations, and mean square errors across all sample sizes. This indicates that the proposed procedure resulted in virtually identical parameter estimates as those from the extant one.

As discussed in Section 3, technically, the proposed procedure allows a compromise between Mode A and Mode B by taking the value of $\alpha_{j}$ between 0 and 1 . As a reviewer suggested, we have investigated the effect of adopting such a third type of mode on parameter estimation. Specifically, we applied the proposed procedure under $\alpha_{\mathrm{j}}=.5$, so that Mode A and Mode B contributed simultaneously to obtaining estimates. As shown in Table 3, this case tended to produce less biased estimates particularly in small samples, whereas it tended to yield larger standard deviations of the estimates. Consequently, its estimates tended to show larger mean square errors than those obtained under Mode A. Thus, at least in this study, adopting $\alpha_{j}=.5$ was of little benefit over using Mode A in estimating parameters. Although permitting a compromise between the two conventional modes is a technically novel feature, as stated earlier, it is unclear what such a compromise indicates substantively, when it can be useful, and how the value of $\alpha_{j}$ can be chosen. 
Table 3: The bias, standard deviation (SD), and mean square error (MSE) of each parameter estimate obtained from the proposed and extant procedures for PLSPM in the first simulation study. $\mathrm{PP}^{1}$ : Proposed procedure under $\alpha_{j}=1 ; \mathrm{PP}^{2}$ : Proposed procedure under $\alpha_{j}=.5 ;$ EP: Extant procedure.

\begin{tabular}{|c|c|c|c|c|c|c|c|c|c|c|}
\hline \multirow{2}{*}{ Parameters } & \multirow{2}{*}{$\mathrm{N}$} & \multicolumn{3}{|c|}{ Bias } & \multicolumn{3}{|c|}{ SD } & \multicolumn{3}{|c|}{ MSE } \\
\hline & & $\mathrm{PP}^{1}$ & $\mathrm{PP}^{2}$ & $\mathrm{EP}$ & $\mathrm{PP}^{1}$ & $\mathrm{PP}^{2}$ & EP & $\mathrm{PP}^{1}$ & $\mathrm{PP}^{2}$ & EP \\
\hline \multirow{3}{*}{$\begin{array}{l}\text { Loading } 1 \\
(.7)\end{array}$} & 25 & .0842 & .0052 & .0842 & .1590 & .2900 & .1633 & .0324 & .0841 & .0338 \\
\hline & 100 & .1067 & .0957 & .1067 & .0537 & .0970 & .0536 & .0143 & .0186 & .0143 \\
\hline & 400 & .1120 & .1092 & .1120 & .0250 & .0448 & .0250 & .0132 & .0139 & .0132 \\
\hline \multirow{3}{*}{$\begin{array}{c}\text { Loading2 } \\
(.7)\end{array}$} & 25 & .0977 & -.0110 & .0973 & .1242 & .2959 & .1241 & .0250 & .0877 & .0249 \\
\hline & 100 & .1064 & .0930 & .1064 & .0519 & .0994 & .0518 & .0140 & .0185 & .0140 \\
\hline & 400 & .1103 & .1078 & .1103 & .0256 & .0467 & .0256 & .0128 & .0138 & .0128 \\
\hline \multirow{3}{*}{$\begin{array}{l}\text { Loading3 } \\
(.7)\end{array}$} & 25 & .0766 & -.0021 & .0775 & .1573 & .3137 & .1543 & .0306 & .0984 & .0298 \\
\hline & 100 & .1106 & .0869 & .1106 & .0490 & .1073 & .0489 & .0146 & .0191 & .0146 \\
\hline & 400 & .1121 & .1068 & .1121 & .0236 & .0468 & .0236 & .0131 & .0136 & .0131 \\
\hline \multirow{3}{*}{$\begin{array}{l}\text { Loading4 } \\
(.7)\end{array}$} & 25 & .1016 & .0672 & .1023 & .1164 & .1813 & .1139 & .0239 & .0374 & .0234 \\
\hline & 100 & .1079 & .1013 & .1079 & .0442 & .0762 & .0440 & .0136 & .0161 & .0136 \\
\hline & 400 & .1110 & .1098 & .1110 & .0210 & .0326 & .0209 & .0128 & .0131 & .0128 \\
\hline \multirow{3}{*}{$\begin{array}{l}\text { Loading5 } \\
\quad(.7)\end{array}$} & 25 & .1042 & .0675 & .1039 & .1136 & .1774 & .1139 & .0237 & .0360 & .02 \\
\hline & 100 & .1092 & .1112 & .1092 & .0461 & .0702 & .0460 & .0141 & .0173 & .0140 \\
\hline & 400 & .1121 & .1113 & .1121 & .0215 & .0315 & .0214 & .0130 & .0134 & .0130 \\
\hline \multirow{3}{*}{$\begin{array}{l}\text { Loading6 } \\
\quad(.7)\end{array}$} & 25 & .0992 & .0617 & .1006 & .1098 & .1993 & .1039 & .0219 & .0435 & .0209 \\
\hline & 100 & .1077 & .1001 & .1077 & .0464 & .0757 & .0465 & .0138 & .0158 & .0138 \\
\hline & 400 & .1120 & .1114 & .1120 & .0215 & .0308 & .0215 & .0130 & .0134 & .0131 \\
\hline \multirow{3}{*}{$\begin{array}{l}\text { Loading7 } \\
\quad(.7)\end{array}$} & 25 & .0938 & .0013 & .0951 & .1569 & .2969 & .1449 & .0334 & .0882 & .0300 \\
\hline & 100 & .1097 & .0930 & .1097 & .0489 & .1044 & .0489 & .0144 & .0195 & .0144 \\
\hline & 400 & .1097 & .1117 & .1097 & .0229 & .0453 & .0229 & .0126 & .0145 & .0126 \\
\hline \multirow{3}{*}{$\begin{array}{l}\text { Loading8 } \\
\quad(.7)\end{array}$} & 25 & .0757 & -.0127 & .0764 & .1837 & .2888 & .1835 & .0395 & .0835 & .0395 \\
\hline & 100 & .1055 & .0844 & .1055 & .0540 & .0983 & .0539 & .0140 & .0168 & .0140 \\
\hline & 400 & .1114 & .1048 & .1114 & .0242 & .0453 & .0242 & .0130 & .0130 & .0130 \\
\hline \multirow{3}{*}{$\begin{array}{l}\text { Loading9 } \\
\quad(.7)\end{array}$} & 25 & .0605 & -.0015 & .0615 & .2162 & .2788 & .2182 & .0504 & .0777 & .0514 \\
\hline & 100 & .1084 & .0966 & . 1084 & .0488 & .1066 & .0488 & .0141 & .0207 & .0141 \\
\hline & 400 & .1125 & .1068 & .1125 & .0224 & .0464 & .0224 & .0132 & .0135 & .0132 \\
\hline \multirow{3}{*}{$\begin{array}{c}\text { Path } 1 \\
(.6)\end{array}$} & 25 & -.1024 & -.0664 & -.1021 & .1655 & .1854 & .1635 & .0379 & .0388 & .0372 \\
\hline & 100 & -.1555 & -.1382 & -.1554 & .0801 & .0808 & .0799 & .0306 & .0256 & .0305 \\
\hline & 400 & -.1531 & -.1451 & -.1531 & .0405 & .0396 & .0405 & .0251 & .0226 & .0251 \\
\hline \multirow{3}{*}{$\begin{array}{c}\text { Path } 2 \\
(.6)\end{array}$} & 25 & -.1091 & -.0703 & -.1091 & .1576 & .1769 & .1573 & .0368 & .0362 & .0366 \\
\hline & 100 & -.1461 & -.1300 & -.1461 & .0812 & .0762 & .0810 & .0279 & .0227 & .0279 \\
\hline & 400 & -.1500 & -.1493 & -.1500 & .0396 & .0401 & .0396 & .0241 & .0239 & .0241 \\
\hline
\end{tabular}

\subsubsection{Simulation 2}

The first simulation study was useful to evaluate how similarly the proposed and extant procedures performed. Nonetheless, this study may be somewhat too simple in that it involved only three blocks of reflective indicators and assumed the same correlations among each block of indicators. Thus, we conducted another simulation study, which considered both formative and reflective indictors as well as different correlations among each block of indicators. Specifically, we used the model specified in Ringle et al. (2009) for the second simulation study. Figure 4 displays the model 
given in Ringle et al. (2009), along with its parameter values. Ringle et al. (2009) did not provide population residual variances. Instead, they provided the population correlation matrix of indicators, derived based on the specified model (see Table 5 in Ringle et al., 2009). We generated multivariate normal data, using the correlation matrix.

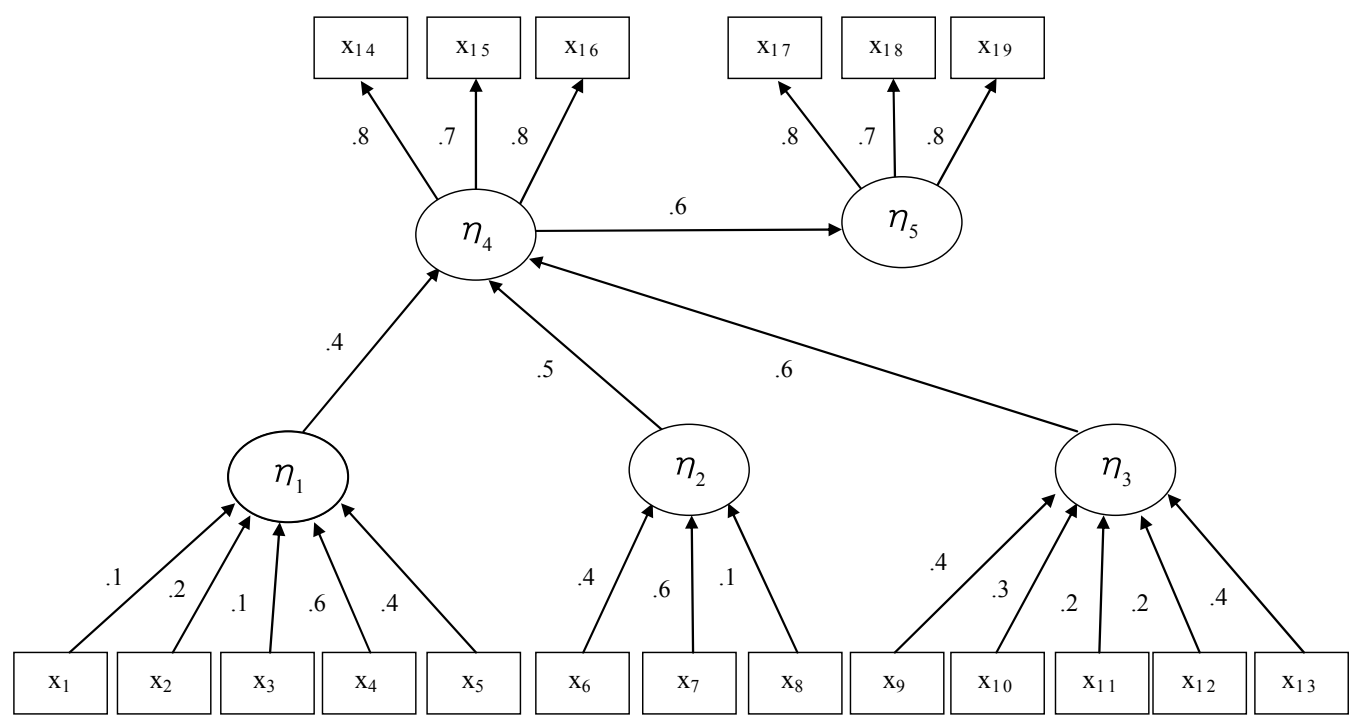

Figure 4: Ringle et al. (2009)'s structural equation model used for the second simulation study.

As in the first simulation study, we considered three different levels of sample size $(\mathrm{N}=25,100,400)$. Five hundred samples were generated at each sample size. We used the same initial values per sample for the proposed and extant procedures. Mode A was applied for estimating the weights for reflective indicators, whereas Mode B was used for estimating those for formative indicators. The path weighting scheme was employed for the extant procedure.

Table 4 provides the bias, standard deviation, and mean square error of each standardized parameter estimate obtained from the two procedures. The parameter estimates of both procedures showed the same behaviors, although it was somewhat difficult to characterize them clearly. For example, some weight estimates for formative indicators were negatively biased, other estimates were positively biased, and the others were biased in different directions over sample size. Conversely, all loading estimates were positively biased regardless of sample size. Two estimates of path coefficients were negatively biased, whereas one estimate was positively biased, across sample sizes. It was dificult to explain where these biases came from because Ringle et al. (2009) did not discuss explicitly whether their population correlation matrix was generated based on the assumption that the latent variables were equivalent to common factors as in the first study. The standard deviations and mean square errors of all parameter estimates decreased with sample size. Importantly, all the parameter estimates obtained from both procedures involved quite similar biases, standard 
Table 4: The bias, standard deviation (SD), and mean square error (MSE) of each parameter estimate obtained from the proposed and extant procedures for PLSPM in the second simulation study.

\begin{tabular}{|c|c|c|c|c|c|c|c|}
\hline \multirow{2}{*}{ Parameters } & \multirow{2}{*}{$\mathrm{N}$} & \multicolumn{2}{|c|}{ Bias } & \multicolumn{2}{|c|}{ SD } & \multicolumn{2}{|c|}{ MSE } \\
\hline & & Proposed & Extant & Proposed & Extant & Proposed & Extant \\
\hline $\begin{array}{c}\text { Weight } 1 \\
(.1)\end{array}$ & $\begin{array}{c}25 \\
100 \\
400\end{array}$ & $\begin{array}{l}-.1443 \\
-.1461 \\
-.1577\end{array}$ & $\begin{array}{l}-.1442 \\
-.1461 \\
-.1579\end{array}$ & $\begin{array}{l}.2812 \\
.1206 \\
.0575\end{array}$ & $\begin{array}{l}.2811 \\
.1206 \\
.0575\end{array}$ & $\begin{array}{l}.0999 \\
.0359 \\
.0282\end{array}$ & $\begin{array}{l}.0998 \\
.0359 \\
.0282 \\
\end{array}$ \\
\hline $\begin{array}{l}\text { Weight } 2 \\
(.2)\end{array}$ & $\begin{array}{c}25 \\
100 \\
400 \\
\end{array}$ & $\begin{array}{l}-.0773 \\
-.0772 \\
-.0655\end{array}$ & $\begin{array}{l}-.0771 \\
-.0770 \\
-.0654\end{array}$ & $\begin{array}{l}.2355 \\
.1149 \\
.0545 \\
\end{array}$ & $\begin{array}{l}.2356 \\
.1149 \\
.0545 \\
\end{array}$ & $\begin{array}{l}.0614 \\
.0192 \\
.0073 \\
\end{array}$ & $\begin{array}{l}.0615 \\
.0191 \\
.0072 \\
\end{array}$ \\
\hline $\begin{array}{c}\text { Weight } 3 \\
(.1)\end{array}$ & $\begin{array}{c}25 \\
100 \\
400 \\
\end{array}$ & $\begin{array}{l}-.1354 \\
-.1391 \\
-.1338\end{array}$ & $\begin{array}{l}-.1356 \\
-.1393 \\
-.1340\end{array}$ & $\begin{array}{l}.2630 \\
.1148 \\
.0519 \\
\end{array}$ & $\begin{array}{l}.2631 \\
.1148 \\
.0519 \\
\end{array}$ & $\begin{array}{l}.0875 \\
.0325 \\
.0206 \\
\end{array}$ & $\begin{array}{l}.0876 \\
.0326 \\
.0207 \\
\end{array}$ \\
\hline $\begin{array}{l}\text { Weight } 4 \\
(.6)\end{array}$ & $\begin{array}{c}25 \\
100 \\
400 \\
\end{array}$ & $\begin{array}{l}.0298 \\
.0614 \\
.0687 \\
\end{array}$ & $\begin{array}{l}.0297 \\
.0615 \\
.0688\end{array}$ & $\begin{array}{l}.2252 \\
.0763 \\
.0366 \\
\end{array}$ & $\begin{array}{l}.2252 \\
.0763 \\
.0366 \\
\end{array}$ & $\begin{array}{l}.0516 \\
.0096 \\
.0061 \\
\end{array}$ & $\begin{array}{l}.0516 \\
.0096 \\
.0061 \\
\end{array}$ \\
\hline $\begin{array}{l}\text { Weight } 5 \\
\quad(.4)\end{array}$ & $\begin{array}{c}25 \\
100 \\
400 \\
\end{array}$ & $\begin{array}{l}.2674 \\
.3090 \\
.3103 \\
\end{array}$ & $\begin{array}{l}.2675 \\
.3089 \\
.3102 \\
\end{array}$ & $\begin{array}{l}.2026 \\
.0724 \\
.0366 \\
\end{array}$ & $\begin{array}{l}.2026 \\
.0724 \\
.0367 \\
\end{array}$ & $\begin{array}{l}.1125 \\
.1007 \\
.0976 \\
\end{array}$ & $\begin{array}{l}.1126 \\
.1007 \\
.0976 \\
\end{array}$ \\
\hline $\begin{array}{l}\text { Weight } 6 \\
(.4)\end{array}$ & $\begin{array}{c}25 \\
100 \\
400 \\
\end{array}$ & $\begin{array}{l}.0294 \\
.1421 \\
.2276 \\
\end{array}$ & $\begin{array}{l}.0299 \\
.1426 \\
.2280 \\
\end{array}$ & $\begin{array}{l}.4651 \\
.3178 \\
.1591 \\
\end{array}$ & $\begin{array}{l}.4649 \\
.3176 \\
.1589 \\
\end{array}$ & $\begin{array}{l}.2172 \\
.1212 \\
.0771 \\
\end{array}$ & $\begin{array}{l}.2171 \\
.1212 \\
.0772 \\
\end{array}$ \\
\hline $\begin{array}{l}\text { Weight } 7 \\
\quad(.6)\end{array}$ & $\begin{array}{c}25 \\
100 \\
400 \\
\end{array}$ & $\begin{array}{c}-.1872 \\
.0410 \\
.1298\end{array}$ & $\begin{array}{c}-.1867 \\
.0410 \\
.1295\end{array}$ & $\begin{array}{l}.4839 \\
.3089 \\
.1492 \\
\end{array}$ & $\begin{array}{l}.4835 \\
.3087 \\
.1491 \\
\end{array}$ & $\begin{array}{l}.2691 \\
.0971 \\
.0391 \\
\end{array}$ & $\begin{array}{l}.2686 \\
.0970 \\
.0390 \\
\end{array}$ \\
\hline $\begin{array}{c}\text { Weight } 8 \\
(.1)\end{array}$ & $\begin{array}{c}25 \\
100 \\
400 \\
\end{array}$ & $\begin{array}{r}.0705 \\
-.0989 \\
-.1255 \\
\end{array}$ & $\begin{array}{c}.0701 \\
-.0991 \\
-.1259 \\
\end{array}$ & $\begin{array}{l}.5018 \\
.3496 \\
.2161 \\
\end{array}$ & $\begin{array}{l}.5017 \\
.3494 \\
.2159 \\
\end{array}$ & $\begin{array}{l}.2568 \\
.1320 \\
.0625 \\
\end{array}$ & $\begin{array}{l}.2566 \\
.1319 \\
.0625 \\
\end{array}$ \\
\hline $\begin{array}{l}\text { Weight9 } \\
(.4)\end{array}$ & $\begin{array}{c}25 \\
100 \\
400 \\
\end{array}$ & $\begin{array}{c}-.2287 \\
-.1280 \\
.1415\end{array}$ & $\begin{array}{c}-.2288 \\
-.1281 \\
.1411\end{array}$ & $\begin{array}{l}.5146 \\
.5045 \\
.4416 \\
\end{array}$ & $\begin{array}{l}.5149 \\
.5046 \\
.4416 \\
\end{array}$ & $\begin{array}{l}.3171 \\
.2709 \\
.2150 \\
\end{array}$ & $\begin{array}{l}.3175 \\
.2710 \\
.2149 \\
\end{array}$ \\
\hline $\begin{array}{c}\text { Weight } 10 \\
(.3)\end{array}$ & $\begin{array}{c}25 \\
100 \\
400 \\
\end{array}$ & $\begin{array}{c}-.1332 \\
-.1598 \\
.0085\end{array}$ & $\begin{array}{c}-.1333 \\
-.1597 \\
.0090\end{array}$ & $\begin{array}{l}.6262 \\
.5498 \\
.4136 \\
\end{array}$ & $\begin{array}{l}.6261 \\
.5498 \\
.4137 \\
\end{array}$ & $\begin{array}{l}.4099 \\
.3278 \\
.1711 \\
\end{array}$ & $\begin{array}{l}.4098 \\
.3278 \\
.1712 \\
\end{array}$ \\
\hline $\begin{array}{c}\text { Weight } 11 \\
(.2)\end{array}$ & $\begin{array}{c}25 \\
100 \\
400 \\
\end{array}$ & $\begin{array}{l}-.1197 \\
-.1571 \\
-.3426\end{array}$ & $\begin{array}{l}-.1194 \\
-.1567 \\
-.3424\end{array}$ & $\begin{array}{l}.6373 \\
.6042 \\
.4836 \\
\end{array}$ & $\begin{array}{l}.6371 \\
.6039 \\
.4834 \\
\end{array}$ & $\begin{array}{l}.4204 \\
.3897 \\
.3513 \\
\end{array}$ & $\begin{array}{l}.4202 \\
.3893 \\
.3510 \\
\end{array}$ \\
\hline $\begin{array}{c}\text { Weight } 12 \\
(.2)\end{array}$ & $\begin{array}{c}25 \\
100 \\
400 \\
\end{array}$ & $\begin{array}{l}-.1170 \\
-.1023 \\
-.0963 \\
\end{array}$ & $\begin{array}{l}-.1169 \\
-.1022 \\
-.0963 \\
\end{array}$ & $\begin{array}{l}.5816 \\
.5153 \\
.4253 \\
\end{array}$ & $\begin{array}{l}.5814 \\
.5152 \\
.4253 \\
\end{array}$ & $\begin{array}{l}.3520 \\
.2760 \\
.1902 \\
\end{array}$ & $\begin{array}{l}.3517 \\
.2759 \\
.1901 \\
\end{array}$ \\
\hline $\begin{array}{c}\text { Weight } 13 \\
(.4)\end{array}$ & $\begin{array}{c}25 \\
100 \\
400 \\
\end{array}$ & $\begin{array}{l}-.3089 \\
-.3531 \\
-.4782\end{array}$ & $\begin{array}{l}-.3088 \\
-.3531 \\
-.4784\end{array}$ & $\begin{array}{l}.5303 \\
.4463 \\
.3686 \\
\end{array}$ & $\begin{array}{l}.5302 \\
.4462 \\
.3687 \\
\end{array}$ & $\begin{array}{l}.3767 \\
.3238 \\
.3645 \\
\end{array}$ & $\begin{array}{l}.3765 \\
.3238 \\
.3648 \\
\end{array}$ \\
\hline $\begin{array}{l}\text { Loading } 1 \\
(.8)\end{array}$ & $\begin{array}{c}25 \\
100 \\
400 \\
\end{array}$ & $\begin{array}{l}.1596 \\
.1623 \\
.1624 \\
\end{array}$ & $\begin{array}{l}.1599 \\
.1623 \\
.1625 \\
\end{array}$ & $\begin{array}{l}.0177 \\
.0074 \\
.0036 \\
\end{array}$ & $\begin{array}{l}.0174 \\
.0074 \\
.0036 \\
\end{array}$ & $\begin{array}{l}.0258 \\
.0264 \\
.0264 \\
\end{array}$ & $\begin{array}{l}.0259 \\
.0264 \\
.0264 \\
\end{array}$ \\
\hline $\begin{array}{l}\text { Loading } 2 \\
\quad(.7)\end{array}$ & $\begin{array}{c}25 \\
100 \\
400 \\
\end{array}$ & $\begin{array}{l}.2347 \\
.2364 \\
.2370 \\
\end{array}$ & $\begin{array}{l}.2346 \\
.2367 \\
.2373 \\
\end{array}$ & $\begin{array}{l}.0265 \\
.0137 \\
.0062 \\
\end{array}$ & $\begin{array}{l}.0268 \\
.0136 \\
.0062 \\
\end{array}$ & $\begin{array}{l}.0558 \\
.0561 \\
.0562 \\
\end{array}$ & $\begin{array}{l}.0558 \\
.0562 \\
.0563 \\
\end{array}$ \\
\hline
\end{tabular}




\begin{tabular}{|c|c|c|c|c|c|c|c|}
\hline \multirow{2}{*}{ Parameters } & \multirow{2}{*}{$\mathrm{N}$} & \multicolumn{2}{|c|}{ Bias } & \multicolumn{2}{|c|}{ SD } & \multicolumn{2}{c|}{ MSE } \\
\cline { 3 - 7 } & & Proposed & Extant & Proposed & Extant & Proposed & Extant \\
\hline Loading 3 & 25 & .1517 & .1515 & .0202 & .0205 & .0234 & .0234 \\
$(.8)$ & 100 & .1533 & .1529 & .0096 & .0098 & .0236 & .0235 \\
& 400 & .1540 & .1536 & .0045 & .0046 & .0237 & .0236 \\
\hline Loading 4 & 25 & .1476 & .1476 & .0266 & .0266 & .0225 & .0225 \\
$(.8)$ & 100 & .1494 & .1494 & .0102 & .0102 & .0224 & .0224 \\
& 400 & .1499 & .1499 & .0052 & .0052 & .0225 & .0225 \\
\hline Loading 5 & 25 & .2337 & .2337 & .0353 & .0353 & .0559 & .0559 \\
$(.7)$ & 100 & .2385 & .2385 & .0135 & .0135 & .0571 & .0571 \\
& 400 & .2390 & .2390 & .0065 & .0065 & .0572 & .0572 \\
\hline Loading 6 & 25 & .1618 & .1618 & .0161 & .0161 & .0264 & .0264 \\
$(.8)$ & 100 & .1632 & .1632 & .0070 & .0070 & .0267 & .0267 \\
& 400 & .1630 & .1630 & .0034 & .0034 & .0266 & .0266 \\
\hline Path 1 & 25 & .3332 & .3329 & .1918 & .1917 & .1478 & .1476 \\
$(.4)$ & 100 & .3827 & .3825 & .0408 & .0409 & .1481 & .1480 \\
& 400 & .3981 & .3980 & .0194 & .0194 & .1589 & .1588 \\
\hline Path 2 & 25 & -.3533 & -.3528 & .1422 & .1423 & .1450 & .1447 \\
$(.5)$ & 100 & -.3047 & -.3044 & .0620 & .0620 & .0967 & .0965 \\
& 400 & -.2934 & -.2932 & .0293 & .0292 & .0869 & .0868 \\
\hline Path 3 & 25 & -.5769 & -.5765 & .1868 & .1865 & .3677 & .3671 \\
$(.6)$ & 100 & -.5737 & -.5736 & .0937 & .0937 & .3379 & .3378 \\
& 400 & -.5618 & -.5618 & .0510 & .0509 & .3182 & .3182 \\
\hline Path 4 & 25 & .0066 & .0075 & .1375 & .1371 & .0189 & .0189 \\
$(.6)$ & 100 & .0224 & .0227 & .0612 & .0611 & .0042 & .0042 \\
& 400 & .0167 & .0168 & .0299 & .0299 & .0012 & .0012 \\
\hline
\end{tabular}

deviations, and mean square errors of all parameter estimates across all sample sizes, indicating that the two procedures yielded almost identical parameter estimates.

\section{Conclusion}

We proposed an alternative estimation procedure for estimating component weights in PLSPM. From technical perspectives, this procedure has several advantages over the extant one. First, it adopts a single optimization criterion to estimate the weights under both Mode A and Mode B. Thus, this addresses the enduring issue of lack of a single optimization criterion in PLSPM. Second, the proposed procedure applies an ALS algorithm to minimize the single criterion. This algorithm has been proven to converge (de Leeuw et al., 1976). In contrast, convergence of the extant algorithm has not been fully proven except for the cases of dealing with only one or two latent variables (Hanafi, 2007; Henseler, 2010). Third, the proposed procedure estimates the inner weights optimally in a least squares sense. On the other hand, in the extant procedure, it is unclear how the existing schemes were derived and in what sense their estimates of the inner weights are optimal. Lastly, the least squares criterion (8) can serve as a vehicle for furthering technical extensions of PLSPM. For example, mult icollinearity among a block of indicators can have a negative influence on the estimation of component weights under Mode B (Esposito Vinzi et al., 2010; Tenenhaus 
\& Tenenhaus, 2011). To address this issue, we may integrate a ridge penalty into (8), as follows.

$$
\varphi={ }_{j=1}^{J} \alpha_{j} S S\left(X_{j}-f_{j} w_{j}\right)+{ }_{J=1}^{J}\left(1-\alpha_{j}\right)\left(S S\left(f_{j}-X_{j} w_{j}\right)+\lambda_{j} S S\left(w_{j}\right)\right),
$$

where $\lambda_{\mathrm{j}}$ is a block wise ridge parameter. Moreover, (8) can be minimized in combination with optimal scaling (e.g., Gifi, 1990; Young, 1981). This nonlinear extension can be of use in dealing with discrete indicators.

Besides these technical implications, the proposed procedure was found to provide quite comparable parameter estimates to those obtained from the extant one in a real

Appendix: A summary of the Lohmöller and ALS algorithms.

\begin{tabular}{|c|c|}
\hline The Lohmöller algorithm & The ALS algorithm \\
\hline 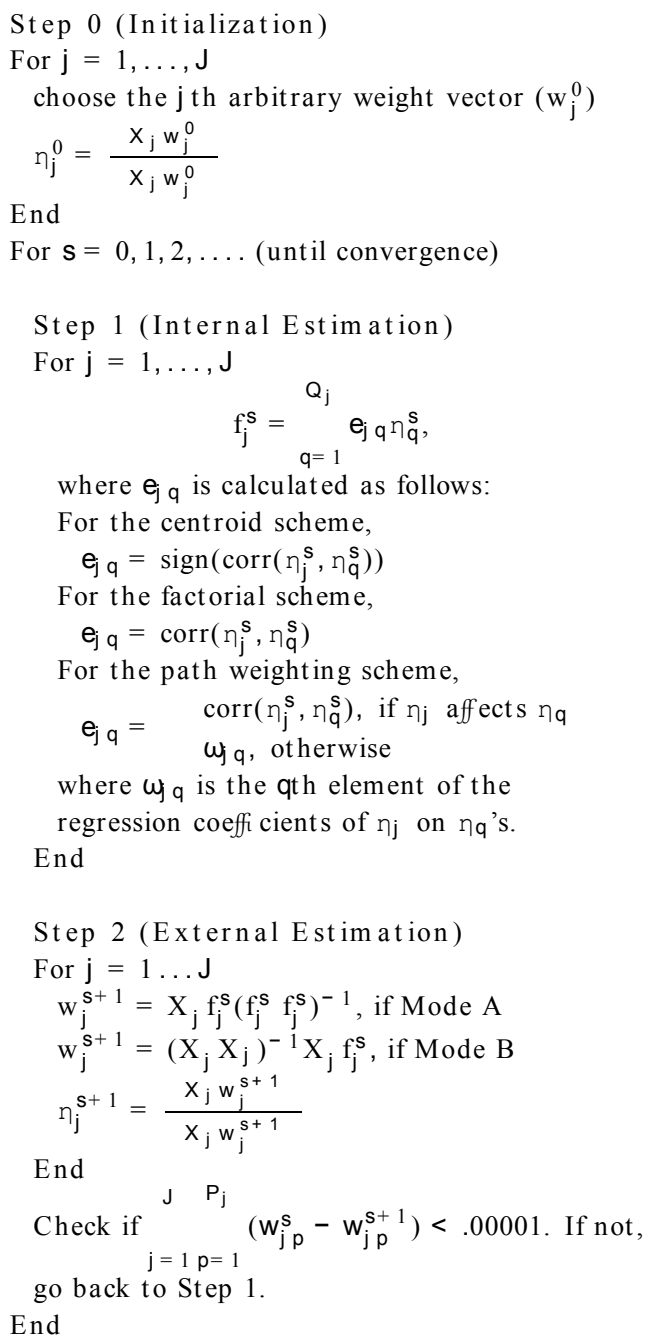 & 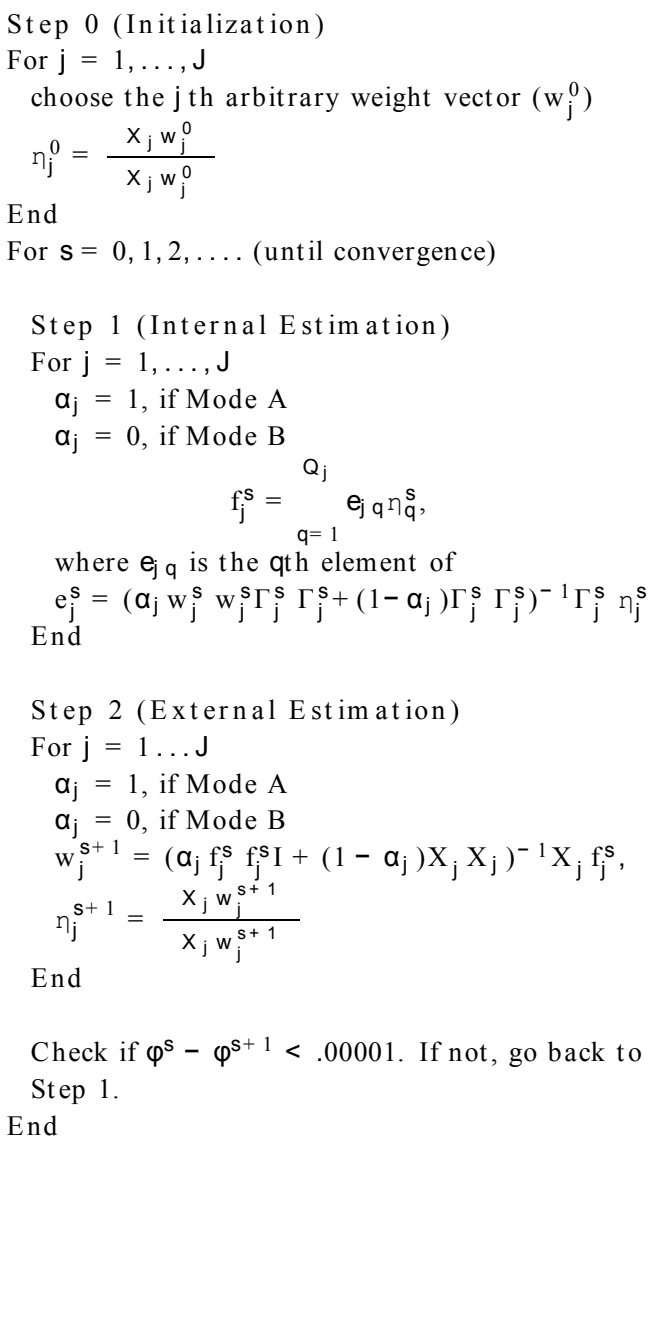 \\
\hline
\end{tabular}


data analysis. In addition, it resulted in virtually identical parameter estimates to those from the extant one in two simulation studies. Although the simulation studies were not exhaustive, they were of help in evaluating how similarly the proposed and extant procedures performed under different models at different sample sizes.

In sum, empirically the proposed procedure performs equally to the extant one, while technically it is well-founded in a least squares sense. Thus, the proposed procedure can serve as a substitute for the extant estimation procedure for PLSPM.

\section{REFERENCES}

Addinsoft (2009). XLSTAT 2009. France: Addinsoft.

Chin, W. W. (2001).PLS-Graph user's guide version 3.0. Soft Modeling Inc.

Coolen, H., \& de Leeuw, J. (1987). Least squares path analysis with optimal scaling. Paper presented at the fifth international symposium of data analysis and informatics. Versailles, France.

de Leeuw, J., Young, F. W., \& Takane, Y. (1976). Additive structure in qualitative data: An alternating least squares method with optimal scaling features. Psychometrika, 41, 471-503.

Dijkstra, T. K. (2010). Latent variables and indices: Herman Wold's basic design and partial least squares. In V. Esposito Vinzi, W. W. Chin, J. Henseler, \& H. Wang (Eds.), Handbook of Partial Least Squares: Concepts, Methods and Applications (pp. 23-46). Berlin: Springer-Verlag.

Esposito Vinzi, V., Trinchera, L., \& Amato, S. (2010). PLS path modeling: from foundations to recent developments and open issues for model assessment and improvement. In V. Esposito Vinzi, W. W. Chin, J. Henseler, \& H. Wang (eds.), Handbook of partial least squares. Concepts, methods, and applications (pp. 47-82). Berlin: Springer-Verlag.

Fornell, C., Johnson, M. D., Anderson, E. W., Cha, J., \& Bryant, B. E. (1996). The American customer satisfaction index: Nature, purpose, and findings. Journal of Marketing, 60, 7-18.

Gifi, A. (1990). Nonlinear multivariate analysis. Chichester: Wiley.

Hanafi, M. (2007). PLS path modeling: computation of latent variables with the estimation mode B. Computational Statistics, 22, 275-292.

Henseler, J. (2010). On the convergence of the partial least squares path modeling algorithm. Computational Statistics, 25, 107-120.

Jöreskog, K. G. (1970). A general method for analysis of covariance structures.Biometrika, 57, 409-426.

Jöreskog, K. G. \& Wold, H. (1982). The ML and PLS techniques for modeling with latent variables: Historical and comparative Aspects. In H. Wold \& K. G. Jöreskog (eds.), Systems under Indirect observation: causality, structure, prediction, part I (pp. 263-270). Amsterdam: North-Holland.

Lohmöller, J.-B. (1984). LVPLS program manual. Cologne, Germany: Zentralarchivfür Empirische Sozialforschung, Universitätzu Köln.

Lohmöller, J.-B. (1989). Latent variable path modeling with partial least squares. New York: Springer-Verlag.

McDonald, R. P. (1996). Path analysis with composite variables. Multivariate Behavioral Research, 31, 239-270.

Ringle, C. M., Götz, O., Wetzels, M., \& Wilson, B. (2009). On the use of formative measurement specifications in structural equation modeling: A Monte Carlo simulation study to compare covariance-based and partial least squares model estimation methodologies. $\mathrm{Mu}-$ nich Personal RePEc Archive Paper No. 15390. Available online at http://mpra.ub.unimuenchen.de/ 15390/. 
Ringle, C. M., Wende, S., \& Will, A. (2005). SmartPLS 2.0 (beta). Hamburg: Germany.

Tenenhaus, A., \& Tenenhaus, M. (2011). Regularized generalized canonical correlation analysis. Psychometrika, 76, 257-284.

Tenenhaus, M. (2008). Component-based structural equation modelling.Total Quality Management and Business Excellence, 19, 871-886.

Tenenhaus, M., Esposito Vinzi, V., Chateline, Y.-M., \& Lauro, C. (2005). PLS Path Modeling.Computational Statistics and Data Analysis, 48, 159-205.

Wold, H. (1966). Estimation of principal components and related methods by iterative least squares. In P. R. Krishnaiah (ed.), Multivariate analysis (pp. 391-420). New York: Academic Press.

Wold, H. (1973). Nonlinear iterative partial least squares (NIPALS) modeling: Some current developments. In P. R. Krishnaiah (ed.), Multivariate analysis (pp. 383-487). New York: Academic Press.

Wold, H. (1982). Soft modeling: The basic design and some extensions. In K. G. Jöreskog \& H. Wold (eds.), Systems under indirect observations II (pp. 1-54). Amsterdam: North-Holland.

Young, F. W. (1981). Quantitative analysis of qualitative data.Psychometrika, 46, 357-388. 